\title{
A Fuzzy TOPSIS with Z-Number and Alpha- Cut in Identifying the Key Factor of Smoking Behaviours in Jordan
}

\author{
Nurnadiah Zamri, Awajan Khaleel Yahia Ibrahim
}

\begin{abstract}
The most famous method when dealing with decision making is Multi-Criteria Decision Making (MCDM). One of the easiest technique from MCDM is Fuzzy Technique for Order Preference by Similarity to Ideal Solution (FTOPSIS). However, there are some circumstances in FTOPSIS still needs to be enhanced. Therefore, this paper concentrates on: 1) to develop FTOPSIS with Z-number and a -cut based MCDM problem; the combination of Z-Number and $\alpha$-cut is seen suitable to solve uncertainty issue due to the additional restriction and reliability parts; 2) to validate the propose method for solving smoking problems in Jordan; three decision makers which are parent, student and health organization are requested to answer all the questionnaires based on smoking behaviour problems. The study presents six steps of FTOPSIS with Z-numbers and $\alpha$ cut to verify the position of the smoking behaviour; 3) to evaluate the efficiency of the proposed method using 10 different number of $\alpha$-cut. Ten different numbers are 0.1 till 0.9. Results illustrate that many Jordanian smoke because they want to lose their weight. From the study, this proposed method opens a new revolution in MCDM area to provide different ways when dealing with decision making problems. Thus, give us variety of techniques in decision making area.
\end{abstract}

Index Terms-a-cut, FTOPSIS, smoking, Z-number.

\section{INTRODUCTION}

In our daily life, one of the most usual task to people is making a decision. Usually, to make a precise decision, it is a need to consider every single alternative and criteria to assess which is the best one [1]. One of the ranking process that involve a group of alternatives and criteria is MultiCriteria Decision Making (MCDM) method. Technique for Order Performance by Similarity to Ideal Solution (TOPSIS) is one of the easiest and simplest in calculation the MCDM method. Fuzzy TOPSIS (FTOPSIS) (developed by [2]) is the expansion of TOPSIS (developed by [3]) with Fuzzy Sets (FSs) method.

FTOPSIS is a method for classifying a group of alternatives using Euclidean distance. FTOPSIS method also known as a method that easy to handle intangible and less cumbersome mathematical calculations. This method has been explored by many researchers such as [4] combined FTOPSIS with Fuzzy Data Development Analysis (DEA). In [5] integrated FTOPSIS and Interval-Valued Intuitionistic Fuzzy Coginitve Maps (IVIFCMs) for model the supplier selection task. In [6] proposed FTOPSIS with Best Worst Method (BWM) for Green Human Resource Management
(GHRM) problem for solving problems in logistics service providers in Sweden. In [7] developed FTOPSIS with Znumbers for assessment on memorandum of understanding at university. This FTOPSIS with Z-numbers by [7] solved the restriction and reliability issues at rating phase. Hence, able to handle uncertainty in a more proper way. However, this FTOPSIS with Z-numbers by [7] technique is still depended only on the distribution's data at the ranking phase and influenced by thrilling values.

In this paper, we focus on ranking phase by [7] by extending FTOPSIS with Z-Numbers and $\alpha$-cuts. Based on [8], $\alpha$-cuts level set based FTOPSIS produce more robust prioritization since more uncertainties can be considered. We also use a real case study on identifying the factors of smoking behaviour among Jordanian to illustrate the propose FTOPSIS with Z-Numbers and $\alpha$-cuts method. The study presents six steps of FTOPSIS with Z-numbers and $\alpha$ cut to determine the final classification of each alternatives. Next, we used the $\alpha$-cut from 0.1 till 0.9 to test the effectiveness of the proposed method.

The rest of this this study can be traced back as; Section II, detailed out the preliminaries of the study. In Section III, development of FTOPSIS with Z-Numbers and $\alpha$-cuts method. Section IV applied a real case study on finding the highest key factor that contributed to smoking behaviour in Jordan. Section V concludes.

\section{PRELIMINARIES}

Definitions that attached to the FTOPSIS and affinity weight are presented in this section.

\section{Definition A. Fuzzy Sets [9]}

Zadeh (the person who introduced Fuzzy Sets (FSs) [9] discussed that a FS can be interpreted as a group of objects that consider grades of membership. The idea of FSs were generalized by classical sets.

Let $H$ be a universe of sets, where ${ }_{\mathrm{A}}(\mathrm{h})$ is a membership function. Each element $h$ in $H$ is a fuzzy number from 0 till 1. Thus, the formula for FSs is as in (1):

$$
\tilde{\mathrm{A}}=\left\{\left(\mathrm{h}, \mu_{\mathrm{A}}(\mathrm{h})\right) \mid \mathrm{h} \in \mathrm{H}\right\}
$$

Revised Manuscript Received on July 10, 2019.

Nurnadiah Zamri, Faculty of Informatics and Computing, Universiti Sultan Zainal Abidin, Besut Campus, 22200 Besut, Terengganu, Malaysia.

Awajan Khaleel Yahia Ibrahim, Faculty of Informatics and Computing, Universiti Sultan Zainal Abidin, Besut Campus, 22200 Besut, Terengganu, Malaysia. 


\section{A FUZZY TOPSIS WITH Z-NUMBER AND ALPHA-CUT IN IDENTIFYING THE KEY FACTOR OF SMOKING BEHAVIOURS IN JORDAN}

\section{Definition B. Triangular Fuzzy Number [9]}

Next, in [10] expended FSs into a triangular fuzzy number (TFN). TFN consists of $\bar{A}$ where $\bar{A}$ can be represented as $\bar{A}=(\mathrm{p}, \mathrm{q}, \mathrm{r})$. Thus, the membership function is given by



We developed steps of FTOPSIS with Z-Numbers and $\alpha$ cut using Definition A and B. The rest of the method development will explain in Section III.

\section{THE STEPS OF FTOPSIS WITH Z-NUMBER AND ALPHA-CUT}

This section highlights four different phases in FTOPSIS. In Rating Phase, FTOPSIS is extended with Z-Numbers method. Two different Z-Numbers' linguistic scale are presented in Table 1 and 2. Weighting Phase also focusses on two different weighting scale using Z-Numbers which are Table 3 and 4. Next, we modified the FTOPSIS and ZNumbers at the Aggregation Phase with $\alpha$-cut method. Lastly, conclude it with the Ranking Phase. Therefore, the overall steps are shown as follows.

\section{A. Rating Phase}

Step 1: Linguistic evaluation and construct decision matrix

Basically, linguistic scales are generated suited based on the decision problems. Here, smoking problems are our main target to solve. Therefore, the linguistic scales are scaled from Very Poor' to 'Very Good' to suit with the problems. Table 1 and 2 list all the linguistic evaluation based on Z-Numbers. This linguistic evaluation is used by all experts to classify each alternative rating based factors.

Table 1: The attributes' linguistic evaluation

\begin{tabular}{|c|c|}
\hline Linguistic Values & Z-Numbers' Values \\
\hline Very Poor (VP) & $(0,0,1)$ \\
\hline Poor (P) & $(0,1,3)$ \\
\hline Medium Poor (MP) & $(1,3,5)$ \\
\hline Fair (F) & $(3,5,7)$ \\
\hline Medium Good (MG) & $(5,7,9)$ \\
\hline Good (G) & $(7,9,10)$ \\
\hline Very Good (VG) & $(9,10,10)$ \\
\hline
\end{tabular}

Table 2: Fuzzy reliability's linguistic evaluation [13]

\begin{tabular}{|c|c|}
\hline Linguistic Values & Z-Numbers' Values \\
\hline Not Sure $(\mathrm{NS})$ & $(0,0,1)$ \\
\hline Quite Sure $(\mathrm{QS})$ & $(1,3,5)$ \\
\hline Sure $(\mathrm{S})$ & $(5,7,9)$ \\
\hline Very Confident $(\mathrm{VC})$ & $(9,10,10)$ \\
\hline
\end{tabular}

Step 2: Normalize the linguistic evaluation

The matrix of FMCDM problem is formulated as in (4). Then, all these linguistic values are normalized as follows:



$$
\begin{aligned}
& Y=\left(\tilde{f}_{i j}, r \tilde{f}_{i j}\right)_{m \times n}, \\
& Y=\left(\tilde{f}_{i j}, r \tilde{f}_{i j}\right)_{m \times n},
\end{aligned}
$$
$\left(\tilde{f}_{i j}, r \tilde{f}_{i j}\right) \quad$ is a Z-Numbers with FS, $1 \leq i \leq m, 1 \leq j \leq n, 1 \leq p \leq k$, and $k$ denotes the number of experts.

\section{B. Weighting Phase}

Step 3: Form the decision matrix's weighted

Table 3 is used to form the decision matrix's weighted of $\bar{W}_{p}$ using Table 3 and in (6) and (7).

Table 3: Linguistic terms of weights for the attributes and their positive and negative

\begin{tabular}{|c|c|}
\hline Linguistic Terms & Fuzzy Set with Z-Numbers \\
\hline Very Low (VL) & $(0,0,0.1)$ \\
\hline Low (L) & $(0 ., 0.1,0.3)$ \\
\hline Medium Low (ML) & $(0.1,0.5,0.7)$ \\
\hline Medium (M) & $(0.3,0.5,0.7)$ \\
\hline Medium High (MH) & $(0.5,0.7,0.9)$ \\
\hline High (H) & $(0.7,0.9,0.1)$ \\
\hline Very High (VH) & $(0.9,1.0,1.0)$ \\
\hline
\end{tabular}

Construct the weighting matrix $\bar{W}_{p}$ of the criteria of the experts and construct the $p$ th average weighting matrix $\bar{W}$, respectively, shown as follows:

$$
\begin{aligned}
& \begin{array}{llll}
f_{1} & f_{2} & \Lambda & f_{n}
\end{array} \\
& \overline{\mathrm{W}}_{\mathrm{p}}=\left(\tilde{\mathrm{w}}_{\mathrm{i}}^{\mathrm{p}}, \mathrm{r} \tilde{\mathrm{w}}_{\mathrm{i}}^{\mathrm{p}}\right)_{1 \times \mathrm{m}}=\left[\begin{array}{lll}
\left.\left(\tilde{\mathrm{w}}_{1}^{\mathrm{p}}, \mathrm{r} \tilde{\mathrm{w}}_{1}^{\mathrm{p}}\right) \quad\left(\tilde{\mathrm{w}}_{2}^{\mathrm{p}}, \mathrm{r} \tilde{\mathrm{w}}_{2}^{\mathrm{p}}\right) \quad \cdots \quad\left(\tilde{\mathrm{w}}_{\mathrm{m}}^{\mathrm{p}}, \mathrm{r} \tilde{\mathrm{w}}_{\mathrm{m}}^{\mathrm{p}}\right)\right]
\end{array}\right] \\
& \bar{W}=(\tilde{w}, r \tilde{w})_{1 \times m}
\end{aligned}
$$

where $\left(\tilde{w}_{i}^{p}, r \tilde{w}_{i}^{p}\right)=\frac{\left(\tilde{w}_{i}^{1}, r \tilde{w}_{i}^{1}\right) \oplus\left(\tilde{w}_{i}^{2}, r \tilde{w}_{i}^{2}\right) \oplus \mathrm{K} \oplus\left(\tilde{w}_{i}^{k}, r \tilde{w}_{i}^{k}\right)}{k}$, $\left(\widetilde{w}_{i}^{p}, r \widetilde{w}_{i}^{p}\right)$ is a linguistic values of Z-Numbers with FS, $1 \leq i \leq m, 1 \leq p \leq k$ and represents the number of decision makers.

Then, the matrix for decision matrix's weighted is shown in (8) as follows. 


$$
\begin{aligned}
& x_{1} \quad x_{2} \quad \Lambda \quad x_{n}
\end{aligned}
$$

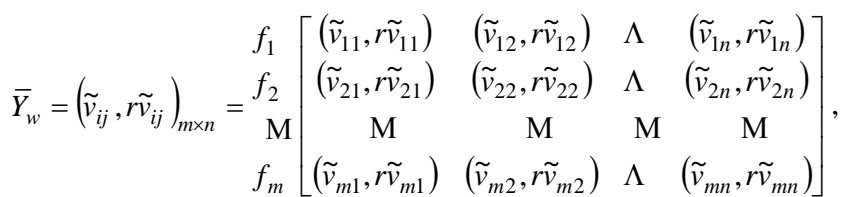

where $\quad\left(\tilde{v}_{i j}, r \tilde{v}_{i j}\right)=\left(\tilde{w}_{i}, r \tilde{w}_{i}\right) \otimes\left(\tilde{f}_{i j}, r \tilde{f}_{i j}\right), \quad 1 \leq i \leq m$, and $1 \leq j \leq n$.

\section{Aggregating Phase}

Step 4: Verify the PIS distance and NIS distance

$A^{*}$ is a positive ideal solutions.

$\left.A^{*}=\mathrm{p}_{1}^{*}, \ldots, \mathrm{p}_{\mathrm{n}}^{*}\right\}=\left\{\left(\max _{j} \mathrm{p}_{\mathrm{ij}} \mid i \in I^{\prime}\right),\left(\min _{j} \mathrm{p}_{\mathrm{ij}} \mid i \in I^{\prime \prime}\right)\right\}$,

$A^{-}$is a negative ideal solutions.

$A^{-}=\left\{\mathrm{p}_{1}, \ldots, \mathrm{p}_{\mathrm{n}}\right\}=\left\{\left(\min _{j} \mathrm{p}_{\mathrm{ij}} \mid i \in I^{\prime}\right),\left(\max _{j} \mathrm{p}_{\mathrm{ij}} \mid i \in I^{\prime \prime}\right)\right\}$,

where $I^{\prime}$ is referred to the positive criteria and $I^{\prime \prime}$ is referred to the negative criteria, which $I^{\prime}$ is associated with the positive attribute, and $I^{\prime \prime}$ is associated with the negative element.

\section{Step 5: Design of PIS distance and NIS distance}

PIS distance is calculated using Euclidean distance

$\left(D_{\mathrm{j}}^{*}, \mathrm{rD}_{\mathrm{j}}^{*}\right)_{\alpha}=\left(\sqrt{\sum_{\mathrm{i}=1}^{\mathrm{n}}\left(\alpha \cdot \tilde{\mathrm{v}}_{\mathrm{ij}}-\alpha \cdot \tilde{\mathrm{v}}_{\mathrm{i}}^{*}\right)^{2}}, \sqrt{\sum_{\mathrm{i}=1}^{\mathrm{n}}\left(\alpha \cdot \tilde{\mathrm{v}}_{\mathrm{ij}}-\alpha \cdot \tilde{\mathrm{v}}_{\mathrm{i}}^{*}\right)^{2}}\right), \mathrm{j}=1, \ldots, \mathrm{J}$.

and NIS distance is also calculated by Euclidean distance.

$$
\left(D_{j}^{-}, r_{j}^{-}\right)_{\alpha}=\left(\sqrt{\sum_{i=1}^{n}\left(\alpha \cdot \tilde{v}_{i j}-\alpha \cdot \tilde{v}_{i}^{-}\right)^{2}}, \sqrt{\sum_{i=1}^{n}\left(\alpha \cdot r \tilde{v}_{i j}-\alpha \cdot \tilde{v}_{i}^{-}\right)^{2}}\right), j=1, \ldots, J .
$$

\section{Ranking Phase}

\section{Step 6: The final calculations of relative closeness}

In (13) is calculated the best of the alternative $x_{i}$ with respect to $f^{*}$,

$$
\left(C_{j}^{*}, r C_{j}^{*}\right)=\frac{\left(\frac{\left(D_{j}\right)}{\left(D_{j}^{*}+D_{j}\right)}, \frac{\left(r D_{j}\right)}{\left(r D_{j}^{*}+r D_{j}\right)}\right)}{2}, j=1, \ldots, J
$$

The most influential alternative is ranked based on (13). A highest value of most influential $C_{j}^{*}$ is referred as the best place over the alternative $D_{j}$. The highest rank calls as the most affective alternative towards ideal solution.

\section{ASSESSMENT ON SMOKING IN JORDAN \& RESULTS}

To verify the proposed method, a real case application is set up in this section. This paper is employed six smoking causes among Jordanian as the alternatives which are
Parental Influence (A1) [10]-[12], Film Star Attraction (A2) [13]-[16], Feel More Adult (A3) [17]-[21], Look Cool/Fashionable (A4) ([22]-[24]), Weight Control (A5) [25]-[28] Parent Neglect (A6) [29]-[31]. Based on six alternatives, four criteria were considered in this studu. These four criteria were Cigars/Pipes (C1) [32]-[34]. Cigarettes (C2) [35]-[39], Chewing Tobacco in the Mouth (C4) [40]-[42]. The four criteria are choose from previous research on smoking. Six alternatives with four criteria are examined by three experts which were D1, D2 and D3 who are experts on smoking behaviour among Jordanian. From three experienced experts, values in form of linguistic data were gathered via three different questionnaires. Next, ten different value of $\alpha$-cut; starting from $0,0.1,0.2, \ldots, 0.9$ are selected to validate the proposed method with real smoking cases. The rest are explained in six steps as follows.

\section{A. Rating Phase}

\section{Step 1: Linguistic evaluation and construct decision matrix}

Based on Table 1 and Table 2, the structure for evaluating the highest key factor lead to smoking behaviours is given in Fig. 1 where considers all the alternatives and criteria.

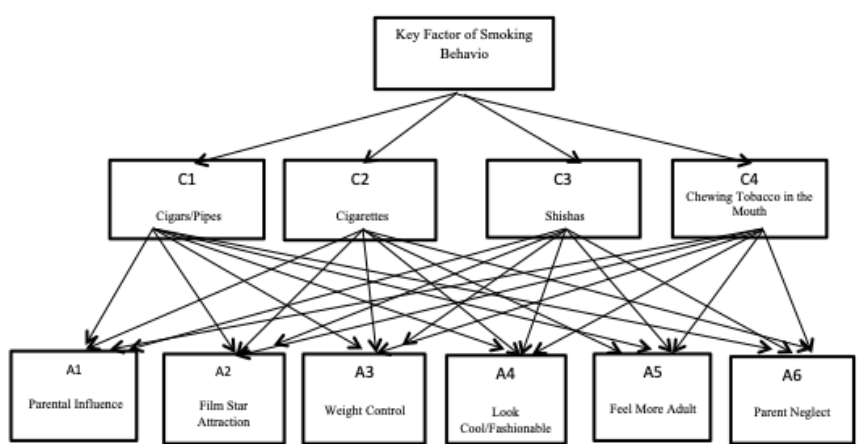

Fig 1: Key factor of smoking behaviour hierarchy

Basically, linguistic scales are generated suited based on the decision problems. Here, smoking problems are our main target to solve. Therefore, the linguistic scales are scaled from Very Poor' to 'Very Good' to suit with the problems. Table 1 lists all the linguistic evaluation based on fuzzy sets. This linguistic evaluation is used by all experts to classify each alternative rating based factors. Thus, these linguistic evaluation are summarized as Table 4.

Table 4: Linguistic evaluations by three different experts

\begin{tabular}{|c|c|c|c|c|c|c|c|}
\hline Criteria & Alternative & \multicolumn{6}{|c|}{ Experts } \\
\cline { 3 - 8 } & & $D_{1}$ & & $D_{2}$ & & $D_{3}$ & \\
\hline Cigars/ & $\mathrm{A} 1$ & $\mathrm{MH}$ & $\mathrm{VC}$ & $\mathrm{H}$ & $\mathrm{VC}$ & $\mathrm{MH}$ & $\mathrm{NS}$ \\
\cline { 2 - 8 } Pipes & $\mathrm{A} 2$ & $\mathrm{M}$ & $\mathrm{VC}$ & $\mathrm{MH}$ & $\mathrm{NS}$ & $\mathrm{H}$ & $\mathrm{VC}$ \\
\cline { 2 - 8 } & $\mathrm{A} 3$ & $\mathrm{H}$ & $\mathrm{S}$ & $\mathrm{VH}$ & $\mathrm{VC}$ & $\mathrm{VL}$ & $\mathrm{QS}$ \\
& $\mathrm{A} 4$ & $\mathrm{~L}$ & $\mathrm{NS}$ & $\mathrm{ML}$ & $\mathrm{S}$ & $\mathrm{L}$ & $\mathrm{QS}$ \\
& $\mathrm{A} 5$ & $\mathrm{MH}$ & $\mathrm{VC}$ & $\mathrm{M}$ & $\mathrm{S}$ & $\mathrm{VL}$ & $\mathrm{QS}$ \\
& $\mathrm{A} 6$ & $\mathrm{H}$ & $\mathrm{NS}$ & $\mathrm{ML}$ & $\mathrm{QS}$ & $\mathrm{VL}$ & $\mathrm{NS}$ \\
\hline Cigarettes & $\mathrm{A} 1$ & $\mathrm{VH}$ & $\mathrm{QS}$ & $\mathrm{MH}$ & $\mathrm{S}$ & $\mathrm{M}$ & $\mathrm{S}$ \\
\cline { 2 - 8 } & $\mathrm{A} 2$ & $\mathrm{ML}$ & $\mathrm{S}$ & $\mathrm{L}$ & $\mathrm{QS}$ & $\mathrm{ML}$ & $\mathrm{VC}$ \\
\hline
\end{tabular}



BEHAVIOURS IN JORDAN

\begin{tabular}{|c|c|c|c|c|c|c|c|}
\hline \multirow{5}{*}{} & A3 & ML & S & MH & S & VL & VC \\
& A4 & MH & S & VH & S & H & S \\
& A5 & L & NS & L & VC & M & VC \\
& A6 & MH & S & VH & S & L & VC \\
\hline Shishas & A1 & MH & VC & L & NS & H & S \\
\cline { 2 - 8 } & A2 & VH & VC & VH & S & M & S \\
\cline { 2 - 8 } & A3 & VH & VC & VH & S & VH & S \\
& A4 & M & QS & M & S & L & VC \\
& A5 & MH & VC & MH & S & VH & QS \\
& A6 & ML & VC & M & S & VL & VC \\
\hline Chewing & A1 & L & QS & L & S & ML & VC \\
\cline { 2 - 8 } Tobacco & A2 & VH & VC & H & NS & H & NS \\
\cline { 2 - 8 } in the & A3 & VL & VC & M & S & MH & VC \\
Mouth & A4 & MH & NS & H & S & VL & VC \\
& A5 & VL & QS & M & S & H & VC \\
& A6 & MH & S & M & S & L & NS \\
\hline
\end{tabular}

Step 2: Normalize the linguistic evaluation

Based on Step 1 and Table 4, all values from experts are normalized using (4). This normalize linguistic evaluations are summarized in matrices as follows.
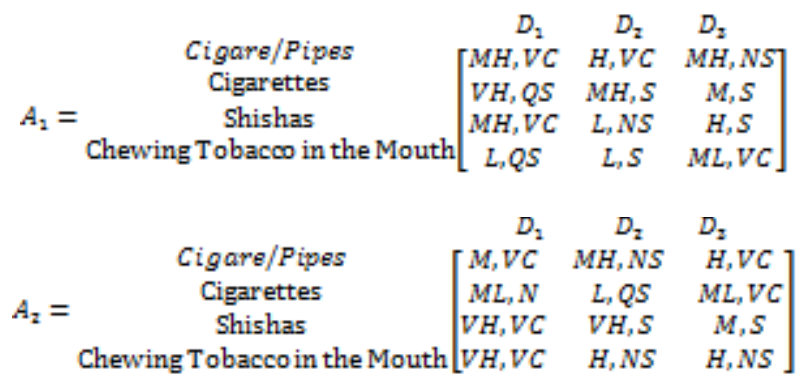

$$
A_{2}=\begin{gathered}
C i g a r e / P i p e s \\
\text { Cigarettes } \\
\text { Shishas } \\
\text { Chewing Tobaceointhe Mouth the }
\end{gathered}\left[\begin{array}{ccc}
D_{2} S & D_{2} & D_{2} \\
M L_{2} S & M H_{2} V & V L_{2} Q S \\
V H_{2} V C & V H_{2} S & V H_{2} S \\
V L_{2} V C & M_{2} S & M H_{2} V C
\end{array}\right]
$$

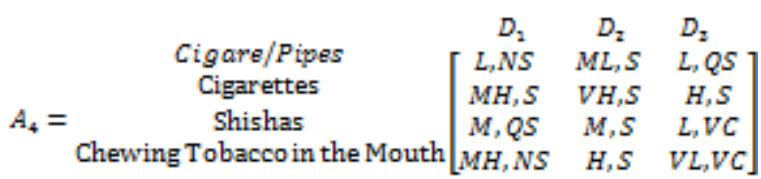

$\left.A_{3}=\begin{array}{cccc}\text { Cigare/Pipes } & D_{2} & D_{2} & D_{2} \\ \text { Cigarettes } & \text { Shishas } \\ \text { Chewing Tobaccointhe Mouth } & M H_{3} V C & M_{3} S & V L_{2} Q S \\ L_{2} N S & L_{2} V C & M_{2} V C \\ M H_{3} V C & M H_{2} S & V H_{3} Q S \\ V L_{2} Q S & M_{2} S & H_{2} V C\end{array}\right]$

$A_{\Delta}=\begin{gathered}\text { Cigare/Pipes } \\ \text { Cigarettes } \\ \text { Shishas } \\ \text { Chewing Tobacoointhe Mouth }\end{gathered}\left[\begin{array}{ccc}D_{2} N S & D_{2} & D_{2} \\ M H_{2} S & V H_{2} S & V L_{2} Q S \\ M L_{2} V C & M_{2} S & V L_{2} V C \\ M H_{3} S & M_{2} S & L_{3} N S\end{array}\right]$

\section{B. Weighting Phase}

Step 3: Construct the weighting for smoking behaviour

Four different criteria are selected to manage the smoking behaviour for weighted decision matrix, which are Cigars/Pipes, Cigarettes, Shishas, and Chewing Tobacco. Thus, all the linguistic evaluation for weights are summarized as Table 5.

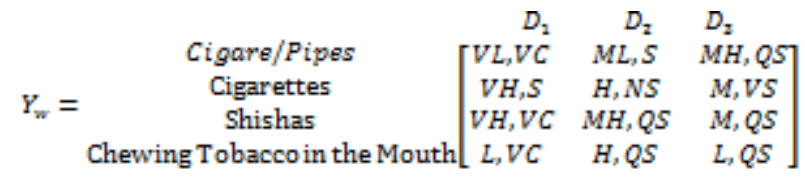

Table 5: Weights of the decision-makers

\begin{tabular}{|c|c|}
\hline & Weight for Each Criteria \\
\hline Cigars/Pipes & $((0.2,0.3333,0.5),(0.5,0.667,0.8))$ \\
\hline Cigarettes & $((0.6333,0.8,0.9),(0.4667,0.5667,0.6667))$ \\
\hline Shishas & $((0.5667,0.7333,0.8667),(0.6333,0.7667,0.83$ \\
& $33))$ \\
\hline Chewing & $((0,0.1,0.3),(0.3667,0.5333,0.6667))$ \\
Tobacco in & \\
Mouth & \\
\hline
\end{tabular}

C. Aggregating Phase

Step 4: Verify the PIS distance and NIS distance

Here, the verification for each PIS distance and the NIS distance are determined as:

$$
\mathrm{A}^{+}=(1,1,1) \mathrm{A}=(0,0,0)
$$

Step 5: Design of PIS distance and NIS distance

The Euclidean distance with different $\alpha$-cuts is used to calculate the distance for each smoking behaviours. Ten different $\alpha$-cuts which are $0,0.1,0.2,0.3,0.4,0.5,0.6,0.7$, 0.9 are tested using (11) and (12).

\section{Ranking Phase}

Step 6: The final calculations of relative closeness

The comparative results based on closeness coefficients between PIS distance and NIS distance are stated as Table 6 till Table 15 as follows.

Table 6: Relative closeness value for $\alpha=0$

\begin{tabular}{|c|c|c|}
\hline & Relative Closeness & Ranking \\
\hline A1 & 0.35202 & 3 \\
\hline A2 & 0.39348 & 2 \\
\hline A3 & 0.312586 & 6 \\
\hline A4 & 0.339356 & 4 \\
\hline A5 & 0.410598 & 1 \\
\hline A6 & 0.316779 & 5 \\
\hline
\end{tabular}

The ranking result for $\alpha=0$ is $A 5>A 2>A 1>A 4>$ $A 6>A 3$

Table 7: Relative closeness value for $=\mathbf{0 . 1}$

\begin{tabular}{|l|c|c|}
\hline & Relative Closeness & Ranking \\
\hline A1 & 0.348965 & 3 \\
\hline A2 & 0.379038 & 2 \\
\hline A3 & 0.309588 & 6 \\
\hline A4 & 0.336327 & 4 \\
\hline A5 & 0.409651 & 1 \\
\hline A6 & 0.313377 & 5 \\
\hline
\end{tabular}


The ranking result for $\alpha=0.1$ is $A 5>A 2>A 1>$ $A 4>A 6>A 3$.

Table 8: Relative closeness value for $\alpha=0.2$

\begin{tabular}{|c|c|c|}
\hline & Relative Closeness & Ranking \\
\hline A1 & 0.346007 & 3 \\
\hline A2 & 0.37718 & 2 \\
\hline A3 & 0.306705 & 6 \\
\hline A4 & 0.3334 & 4 \\
\hline A5 & 0.408775 & 1 \\
\hline A6 & 0.31008 & 5 \\
\hline
\end{tabular}

The ranking result for $\alpha=0.2$ is $A 5>A 2>A 1>$ $A 4>A 6>A 3$.

Table 9: Relative closeness value for $\alpha=0.3$

\begin{tabular}{|c|c|c|}
\hline & Relative Closeness & Ranking \\
\hline A1 & 0.343169 & 3 \\
\hline A2 & 0.375419 & 2 \\
\hline A3 & 0.303955 & 6 \\
\hline A4 & 0.330594 & 4 \\
\hline A5 & 0.407977 & 1 \\
\hline A6 & 0.30691 & 5 \\
\hline
\end{tabular}

The ranking result for $\alpha=0.3$ is $A 5>A 2>A 1>$ $A 4>A 6>A 3$.

Table 10: Relative closeness value for $\alpha=0.4$

\begin{tabular}{|c|c|c|}
\hline & Relative Closeness & Ranking \\
\hline A1 & 0.335882 & 3 \\
\hline A2 & 0.367563 & 2 \\
\hline A3 & 0.29607 & 6 \\
\hline A4 & 0.321911 & 4 \\
\hline A5 & 0.402133 & 1 \\
\hline A6 & 0.298703 & 5 \\
\hline
\end{tabular}

The ranking result for $\alpha=0.4$ is $A 5>A 2>A 1>$ $A 4>A 6>A 3$.

Table 11: Relative closeness value for $\alpha=0.5$

\begin{tabular}{|c|c|c|}
\hline & Relative Closeness & Ranking \\
\hline A1 & 0.337954 & 3 \\
\hline A2 & 0.372245 & 2 \\
\hline A3 & 0.298945 & 6 \\
\hline A4 & 0.325435 & 4 \\
\hline A5 & 0.406642 & 1 \\
\hline A6 & 0.301053 & 5 \\
\hline
\end{tabular}

The ranking result for $\alpha=0.5$ is $A 5>A 2>A 1>$ $A 4>A 6>A 3$.

Table 12: Relative closeness value for $\alpha=0.6$

\begin{tabular}{|c|c|c|}
\hline & Relative Closeness & Ranking \\
\hline A1 & 0.335637 & 3 \\
\hline A2 & 0.370861 & 2 \\
\hline A3 & 0.296733 & 6 \\
\hline A4 & 0.323132 & 4 \\
\hline A5 & 0.406121 & 1 \\
\hline A6 & 0.298426 & 5 \\
\hline
\end{tabular}

The ranking result for $\alpha=0.6$ is $A 5>A 2>A 1>$ $A 4>A 6>A 3$.

Table 13: Relative closeness value for $\alpha=0.7$

\begin{tabular}{|c|c|c|}
\hline & Relative Closeness & Ranking \\
\hline A1 & 0.326776 & 3 \\
\hline A2 & 0.360026 & 2 \\
\hline A3 & 0.286998 & 5 \\
\hline A4 & 0.310682 & 4 \\
\hline A5 & 0.394732 & 1 \\
\hline A6 & 0.286948 & 6 \\
\hline
\end{tabular}

The ranking result for $\alpha=0.7$ is $A 5>A 2>A 1>$ $A 4>A 3>A 6$.

Table 14: Relative closeness value for $\alpha=0.8$

\begin{tabular}{|c|c|c|}
\hline & Relative Closeness & Ranking \\
\hline A1 & 0.330283 & 3 \\
\hline A2 & 0.367723 & 2 \\
\hline A3 & 0.29163 & 6 \\
\hline A4 & 0.317711 & 4 \\
\hline A5 & 0.405272 & 1 \\
\hline A6 & 0.292202 & 5 \\
\hline
\end{tabular}

The ranking result for $\alpha=0.9$ is $A 5>A 2>A 1>$ $A 4>A 6>A 3$.

Table 15: Relative closeness value for $\alpha=0.9$

\begin{tabular}{|c|c|c|}
\hline & Relative Closeness & Ranking \\
\hline A1 & 0.330283 & 3 \\
\hline A2 & 0.367723 & 2 \\
\hline A3 & 0.29163 & 6 \\
\hline A4 & 0.317711 & 4 \\
\hline A5 & 0.405272 & 1 \\
\hline A6 & 0.292202 & 5 \\
\hline
\end{tabular}

In order to validate this proposed method, we list out all the relative closeness ranking from Table 6 till Table 15 as follows;

$$
\begin{array}{ll}
\alpha=0.0 & A 5>A 2>A 1>A 4>A 6>A 3 . \\
\alpha=0.1 & A 5>A 2>A 1>A 4>A 6>A 3 . \\
\alpha=0.2 & A 5>A 2>A 1>A 4>A 6>A 3 . \\
\alpha=0.3 & A 5>A 2>A 1>A 4>A 6>A 3 . \\
\alpha=0.4 & A 5>A 2>A 1>A 4>A 6>A 3 . \\
\alpha=0.5 & A 5>A 2>A 1>A 4>A 6>A 3 . \\
\alpha=0.6 & A 5>A 2>A 1>A 4>A 6>A 3 . \\
\alpha=0.7 & A 5>A 2>A 1>A 4>A 3>A 6 . \\
\alpha=0.8 & A 5>A 2>A 1>A 4>A 6>A 3 . \\
\alpha=0.9 & A 5>A 2>A 1>A 4>A 6>A 3 .
\end{array}
$$




\section{A FUZZY TOPSIS WITH Z-NUMBER AND ALPHA-CUT IN IDENTIFYING THE KEY FACTOR OF SMOKING BEHAVIOURS IN JORDAN}

Based on the outcomes, we can accomplished that A5 which is weight loss is the main highest key factor that contributed to smoking behaviour in Jordan. This ranking result obtained from ten different $\alpha$-cuts which are $0,0.1$, $0.2,0.3,0.4,0.5,0.6,0.7,0.8$ and 0.9 . The results obtained from $\alpha$-cuts $=0.1$ till 0.9 are same, but slightly different for $\alpha$-cuts $=0.7$. The slight changes between A6 and A3 maybe due to the inconsistency of certain steps in $\alpha$-cuts $=0.7$. Overall, we can concluded that the ranking for choosing the most key factor for smoking behaviour is $A 5>A 2>A 1>$ $A 4>A 6>A 3$. Meaning that, the suggested method is stable and suitable for other decision making problems.

\section{v. CONCLUSION}

FTOPSIS with Z-Numbers created new decision making's environment that considers reliability and restriction. This paper extended FTOPSIS with Z-numbers on the aggregating phase. A new aggregating phase of FTOPSIS with Z-Numbers was constructed to replace the previous euclidean distance. In this proposed FTOPSIS with Z-Numbers, ten $\alpha$-cuts were built for comparison of ranking values. A real case study on identifying the key factor of smoking behaviours in Jordan was applied to the proposed method. Six alternatives and five criteria were used to identify this key factor. Results show that, weight control is the most key factor that contributes to smoking behaviour in Jordan. Many Jordanian loves to smoke due to lose their weights. As a conclusion, the developed method is capable to solve FMCDM cases in a more intelligible due to the $\alpha$ cuts' benefit. For upcoming works, it is suggested to integrate the $\alpha$-cuts with the different aggregation method. Properties for the integrated method can be explored.

\section{ACKNOWLEDGMENT}

This research was supported by Pusat Pengurusan Kecemerlangan dan Inkubator Penyelidikan, Universiti Sultan Zainal Abidin.

\section{REFERENCES} Herrera-Viedma, "Dealing with incomplete information in linguistic group decision making by means of Interval Type-2 Fuzzy Sets," International Journal of Intelligent Systems, 34(6), 2019, pp. 1-20.

2. C. T. Chen, "Extensions of the TOPSIS for group decisionmaking under fuzzy environment," Fuzzy Sets and Systems, 114(1), 2000, pp. 1-9.

3. C. L. Hwang, and K. Yoon, Multiple Attribute Decision Making: Methods and Applications. New York: SpringerVerlag, 1981

4. K. Rashidi, and K. Cullinane, "A comparison of fuzzy DEA and fuzzy TOPSIS in sustainable supplier selection: Implications for sourcing strategy," Expert Systems with Applications, 121, 2019, pp. 266-281.

5. P. Hajek, and W. Froelich, "Integrating TOPSIS with intervalvalued intuitionistic fuzzy cognitive maps for effective group decision making," Information Sciences, 485, 2019, pp. 394412. of GHRM practices using BWM and Fuzzy TOPSIS," Journal of Environmental Management, 226, 2018, pp. 201-216.

7. K. Y. Awajan, and N. Zamri, "A fuzzy TOPSIS with Znumbers method for assessment of memorandu, of
1. R. Urena, G. Kou, J. Wu, F. Chiclana, and E.

6. H. Gupta, "Assessing organizations performance on the basis

understanding at university," International Journal of Engineering and Technology, 7(3.28), 2018, pp. 149-152.

8. L. Dymova, P. Sewastjanov, and A. Tikhonenko, "An interval type-2 fuzzy extension of the TOPSIS method using alphacuts," Knowledge-Based System, 83, 2015, pp. 116-127.

9. L. A. Zadeh, "The concept of a linguistic variable and its application to approximate reasoning-I," Journal of Information Sciences, 8(3), 1975, pp. 199-249.

10. R. C. Engels, F. Vitaro, E. D. E. Blokland, R. de Kemp, and R. H. Scholte, "Influence and selection processes in friendships and adolescent smoking behaviour: The role of parental smoking," Journal of Adolescence, 27(5), 2004, pp. 531-544.

11. A. M. Gecková, R. Stewart, J. P. Van Dijk, O. G. Orosová, J. W. Groothoff, and D. Post, "Influence of socio-economic status, parents and peers on smoking behaviour of adolescents," European Addiction Research, 11(4), 2005, pp. 204-209.

12. E. Bergagna, and S. Tartaglia, "The relation of modelling and the perception of parental care with adolescent smoking: A cross-sectional study," European Journal of Developmental Psychology, 16(4), 2018, pp. 476-487.

13. A. Jain, P. Lata, A. R. Goyal, S. Khandelwal, and G. Jain, "Socio-cultural impact of film celebrities on teenagers: An empirical study," International Journal of Indian Culture and Business Management, 11(3), 2015, pp. 308-322.

14. World Health Organization (WHO), Smoke-free movies: From evidence to action. Geneva: WHO, 2015.

15. I. Newman, and J. DeFrain, "Why smoke?," in Tobacco Use and Intimate Relationships: Smokers and Non-Smokers Tell Their Stories, I. Newman and J. DeFrain, Eds. Cham: Palgrave Macmillan, 2018, pp. 137-151.

16. A. B. Barker, M. O. Breton, J. Cranwell, J. Britton, and R. L. Murray, "Population exposure to smoking and tobacco branding in the UK reality show 'Love Island'," Tobacco Control, 27(6), 2018, pp. 709-711.

17. E. Brennan, S. Durkin, K. Coomber, M. Zacher, M. Scollo, and M. Wakefield, "Are quitting-related cognitions and behaviours predicted by proximal responses to plain packaging with larger health warnings? Findings from a national cohort study with Australian adult smokers," Tobacco Control, 24(Suppl 2), 2015, pp. ii33-ii41.

18. J., Hoek, and C. Robertson, "How do young adult female smokers interpret dissuasive cigarette sticks? A qualitative analysis," Journal of Social Marketing, 5(1), 2015, pp. 21-39.

19. J. A. Matheson, "Prices and social behaviour: Evidence from adult smoking in Canadian Aboriginal communities," Canadian Journal of Economics/Revue Canadienne D'économique, 48(5), 2015, pp. 1661-1693.

20. J. M. FitzGerald, I. Poureslami, and J. Shum, "Assessing beliefs and risk perceptions on smoking and smoking cessation in immigrant Chinese adult smokers residing in Vancouver, Canada: A cross-sectional study," BMJ Open, 5(2), 2015, pp. 1-9.

21. N. Hooper, C. Dack, M. Karekla, A. Niyazi, and L. McHugh, "Cognitive defusion versus experiential avoidance in the reduction of smoking behaviour: An experimental and preliminary investigation," Addiction Research and Theory, 26(5), 2018, pp. 414-420.

22. K. Choi, "The associations between exposure to tobacco coupons and predictors of smoking behaviours among US youth," Tobacco Control, 25(2), 2015, pp. 232-235

23. N. McKeganey, and M. Barnard, "Change and continuity in vaping and smoking by young people: A qualitative case study of a friendship group," International Journal of Environmental Research and Public Health, 15(5), 2018, pp. 1008 . 
24. A. S. R. Alsubaie, "Prevalence and determinants of smoking behavior among male school adolescents in Saudi Arabia," International Journal of Adolescent Medicine and Health, 2018, pp. 1-6.

25. C. Shang, F. J. Chaloupka, G. T. Fong, M. Thompson, M. Siahpush, and W. Ridgeway, "Weight control belief and its impact on the effectiveness of tobacco control policies on quit attempts: findings from the ITC 4 Country Project," Tobacco Control, 24, 2015, pp. iii4i - iii47.

26. T. J. Brown, A. Todd, C. O'Malley, H. J. Moore, A. K. Husband, C. Bambra, A. Kasim, F. F. Sniehotta, L. Steed, S. Smith, and L. Nield, "Community pharmacy-delivered interventions for public health priorities: A systematic review of interventions for alcohol reduction, smoking cessation and weight management, including meta-analysis for smoking cessation," BMJ Open, 6(2), 2016, pp. 1-18.

27. I. Santos, F. F. Sniehotta, M. M. Marques, E. V. Carraça, and P. J. Teixeira, "Prevalence of personal weight control attempts in adults: A systematic review and meta-analysis," Obesity Reviews, 18(1), 2017, pp. 32-50.

28. S. N. Oshi, D. C. Oshi, S. Weaver, C. F. Agu, P. WhitehorneSmith, T. Ricketts-Roomes, I. A. Meka, T. Rae, and W. D. Abel, "A school-based study of the influence of students' relationship with teachers on their cigarette smoking behaviour in Jamaican," Asian Pacific Journal of Cancer Prevention, 19(S1), 2018, pp. 7-12.

29. S. Thomas, and S. Deb, "Evidence concerning potential risk behaviour and psychological distress of Indian emerging adults," International Journal of Applied Research, 2(8), 2016, pp. 1-12.

30. S. Özdemir, "Analysis of deviant friends' mediator effect on relationships between adolescent risk behaviours and peer bullying, abuse experiences and psychological resilience," Education and Science/Egitim ve Bilim, 43(195), 2018, pp. 223-239.

31. M. K. Possi, "Effects of drug abuse on cognitive and social behaviours: A potential problem among youth in Tanzania," Utafiti Journal, 3(1), 1996, pp. 111-128.

32. I. T. Agaku, and H. R. Alpert, "Trends in annual sales and current use of cigarettes, cigars, roll-your-own tobacco, pipes, and smokeless tobacco among US adults, 20022012," Tobacco Control, 25(4), 2016, pp. 451-457.

33. J. Ball, J. Stanley, N. Wilson, T. Blakely, and R. Edwards, "Smoking prevalence in New Zealand from 1996-2015: A critical review of national data sources to inform progress toward the smokefree 2025 goal," New Zealand Medical Journal, 129(1439), 2016, pp. 11-22.

34. C. Cannonier, M. G. Burke, and K. Steward, "Smoking, health and academic outcomes: Evidence from a limited smoking campus policy," Health Economics, Policy and Law, 14(2), 2019, pp. 205-230.

35. S. J. Ronaldson, L. Dyson, L. Clark, C. E. Hewitt, D. J. Torgerson, B. G. Cooper, M. Kearney, W. Laughey, R. Raghunath, L. Steele, and R. Rhodes, "The impact of lung function case-finding tests on smoking behaviour: A nested randomised trial within a case-finding cohort," Health Science Reports, 1(6), 2018, pp. 1-9.

36. R. Saunders, Goal-directed tobacco seeking: A study examining the impact of stress and other factors on smoking behaviour. PhD thesis, University of Huddersfield: University of Huddersfield, 2018.

37. A. N. Al-Dabbous, A. R. Khan, S. A. Al-Tamimi, M. Shalash, A. D. Bajoga, and M. J. Malek, "Oxides of carbon, particulate matters and volatile organic compounds impact on indoor air quality during waterpipe smoking," International Journal of Environmental Science and Technology, 16(6), 2019, pp. 2849-2854.

38. R. Bahelah, K. D. Ward, Z. B. Taleb, J. R. DiFranza, T. Eissenberg, R. Jaber, and W. Maziak, "Determinants of progression of nicotine dependence symptoms in adolescent waterpipe smokers," Tobacco Control, 28(3), 2019, pp. 254260.

39. G. Jiang, S. Aldamer, and A. Bendania, "Smoking behaviour among male students in a Saudi University," Eastern Mediterranean Health Journal, 24(5), 2018, pp. 411-418.

40. B. V. Prakruthi, D. B. Nandini, M. Donoghue, S. B. Praveen, K. M. Kumar, and R. Ashwini, "Effects of salivary thiocyanate levels on oral mucosa in young adult smokers: A biochemical and cytological study," Journal of Oral and Maxillofacial Pathology, 22(2), 2018, pp. 204-209.

41. A. Kumar, A. Tiwari, A. Gadiyar, R. B. Gaunkar, and A. K. Kamat, "Assessment of readiness to quit tobacco among patients with oral potentially malignant disorders using transtheoretical model," Journal of Education and Health Promotion, 7, 2018, 9.

42. B. Getachew, J. B. Payne, M. Vu, D. Pillai, J. Shah, H. Levine, and C. J. Berg, "Perceptions of alternative tobacco products, anti-tobacco media, and tobacco regulation among young adults: A qualitative study," American Journal of Health Behavior, 42(4), 2018, pp. 118-130. 